\title{
Menstrual function in workers exposed to toluene
}

\author{
Tze Pin Ng, Swee Cheng Foo, Theresa Yoong
}

\begin{abstract}
Rates of menstrual disorders were studied in 231 female production workers with high exposure to toluene (mean 88 (range 50-150 ppm) in a factory manufacturing audio speakers and compared with a control group of 58 female production workers in other departments in the same factory who had little or no exposure to toluene (0-25 $\mathrm{ppm})$. An external community control group of 187 working class women under routine care at public maternal and child health centres were also studied. Detailed menstrual and reproductive histories were obtained by personal interview using a structured questionnaire. The rates for dysfunctional uterine bleeding (cycle irregularity and prolonged or heavy menstrual bleeding) were similar in all groups. Dysmenorrhoea seemed to occur more often in the women highly exposed to toluene compared with women at maternal and child health centres, but not compared with factory controls with low exposure to toluene. There was no evidence that dysfunctional uterine bleeding was likely to result from exposure to toluene. It is uncertain whether dysmenorrhoea was associated specifically with exposure to toluene, as other behavioural and work related factors may also result in dysmenorrhoea.
\end{abstract}

(British Journal of Industrial Medicine 1992;49:799-803)

Occupational exposure to toluene is widespread as it is commonly used as a solvent in the manufacture and industrial applications of paints, thinners, adhesives, inks, and pharmaceutical products. Few studies have investigated the effects of toluene specifically on the gonads and hormones in occupationally exposed women but some have reported menstrual disorders in workers exposed to toluene. For instance, prolonged and heavy bleeding was more frequent in women exposed to benzene, toluene, and xylene.' Related studies of menstrual function in women

Department of Community, Occupational, and Family Medicine, National University of Singapore T P Ng, S C Foo

Health Services for the Elderly, Ministry of Health, Singapore

T Yoong working in the production of electrical insulating materials have reported that the women experienced a greater frequency of polymenorrhoea, dysmenorrhoea, and irregular cycles than controls. ${ }^{2-1}$ Exposed women were also stated to be more likely to experience changes in menstrual function (increased blood loss, menstrual pain, and alteration of cycle duration) after starting work in the industry. These studies have been critically reviewed ${ }^{j}$ and it was concluded that the effects on menstrual function could not be readily attributed to toluene alone as the workers were also exposed to other chemicals. It seems also that in the series of separate studies ${ }^{2-4}$ the same group of women was investigated several times over. Also, the controls used were office workers in the same factory. These might be different from production workers in terms of socioeconomic situation, nutrition, and general working conditions, all of which may affect gynaecological function.

The present study was undertaken to assess the menstrual function of female workers exposed to a single solvent-toluene. Effects on pregnancies among married women were also studied and are reported elsewhere in this journal.

\section{Materials and methods}

The factory chosen manufactured audio coils and speakers. Environmental assessment of exposure to airborne toluene was carried out in 1987 using diffuse personal sampling tubes packed with tenac GC (DCA, Dosimeter Corp, USA), and blood toluene concentrations were estimated from finger prick blood. Details of the environmental and biological monitoring have been described in previous papers. $^{67}$

The workers were exposed to fairly constant concentrations of toluene during the workshift. A number were exposed to high concentrations of airborne toluene mean 88 (range 50-150) ppm, on two floors in the factory building where speaker parts were finally assembled by bonding with large quantities of resinous glues (final bond assembly). The solvent was exclusively toluene. In two other departments in the same building, where cones and coils were made, workers were exposed to low or negligible toluene $(0-25 \mathrm{ppm})$ arising from small amounts of hot pressing and bonding work. Some cross contamination occurred from high exposure 
areas, as the workrooms were equipped with a total recirculation air conditioning system. Some workers in the departments with low exposure to toluene were also exposed to low levels of other environmental hazards-namely, noise, heat, lead, methanol, and methyl ethyl ketone. Hygiene assessments indicated that the exposure of workers to these potential hazards were well within acceptable (American Conference of Governmental Industrial Hygienists threshold limit values) limits. All the female production workers did similar assembly jobs, sitting down, and with little or no lifting or carrying of heavy loads. They all worked regular day hours.

A total of 755 workers were employed in assembly line production work, including male, part time, and permanent nightshift workers. The number of women on full time regular day employment was 343 , and of these 311 women were successfully interviewed ( $91 \%$ response).

We also included an external community control group of women who were receiving routine antenatal and postnatal care in several public (government) maternal and child health centres situated in industrial areas among which the factory was located. A total of 190 attending women were consecutively interviewed, with no refusals. Twenty nine women $(15 \%)$ were currently employed in factory production jobs and 104 were housewives $(55 \%)$. Among the current housewives, 66 were previously employed in factory production jobs ( $35 \%$ of total).

The interviews were conducted through a structured questionnaire by two trained women field investigators. The principal parts of the questionnaire included questions related to: (1) occupational exposure: date of first employment in the factory, department worked, job transfers, if any, within the factory, other previous exposure to solvents and other hazardous metals and chemicals, shift work, frequent heavy lifting, and carrying of loads on the job; (2) personal habits such as smoking and alcohol consumption; (3) medical histories and gynaecological data: these included the usual, shortest, and longest intervals between successive onsets of menstruation; usual, shortest, and longest duration of menstrual flow; comparative amount of menstrual flow (whether more, less, or the same as in the past since menarche); comparative frequency and severity of menstrual cramps and associated abdominal and back pain or ache during menstruation (whether more, less, or the same as in the past since menarche); severe dysmenorrhoea was defined as menstrual cramps and pain requiring regular attention of a doctor and pharmacological relief or medical leave. The onset of changes in menstrual function over time, if any, was determined from the questionnaire without proximal or direct reference to the date of employment at the factory. All subjects were also asked questions concerning current (or recent) and previous use of hormonal contraceptives (oral or depot) and intrauterine devices.

Menstrual disturbances were characterised by (1) cycle irregularities: short cycles if either or both of the shortest and longest cycles were less than 14 days; long cycles if either or both of the shortest and longest cycles were more than $\mathbf{4 2}$ days; both short and long cycles if the shortest cycle was less than 14 days and the longest cycle was more than 42 days; (2) prolonged menstruation: defined as menstrual flow lasting more than seven days.

Table 1 Basic characteristics of subjects by exposure groups

\begin{tabular}{|c|c|c|c|}
\hline & MCH women & Low exposure & High exposure \\
\hline No of subjects & 187 & 58 & 231 \\
\hline \multicolumn{4}{|l|}{ Race: } \\
\hline Chinese & $79(42 \cdot 2)$ & $41(70 \cdot 1)$ & $151(65 \cdot 4)$ \\
\hline Malays & $94(50 \cdot 3)$ & $5(8.6)$ & $28(12 \cdot 1)$ \\
\hline Indians and others & $14(7 \cdot 5)$ & $12(20 \cdot 1)$ & $52(22 \cdot 5)$ \\
\hline Age $(y)$ & $28 \cdot 6($ SD $4 \cdot 4)$ & $26.8($ SD 5.9$)$ & $25 \cdot 6($ SD $5 \cdot 5)$ \\
\hline Years employed at factory & - & $6.7(\mathrm{SD} 4.4)$ & $6.0(\mathrm{SD} 4.0)$ \\
\hline Age of menarche & $12 \cdot 8(\operatorname{SD~} 2 \cdot 2)$ & $13 \cdot 2(\mathrm{SD} 3 \cdot 0)$ & $13 \cdot 5(\mathrm{SD} 2 \cdot 3)$ \\
\hline \multicolumn{4}{|l|}{ Marital state: } \\
\hline Married & $187(100 \cdot 0)$ & $24(41 \cdot 4)$ & $64(27 \cdot 7)$ \\
\hline Single & $0(0.0)$ & $34(58 \cdot 6)$ & $167(72 \cdot 3)$ \\
\hline \multicolumn{4}{|l|}{ Current (or recent) contraceptives: } \\
\hline Oral & $1(0 \cdot 5)$ & $3(5 \cdot 2)$ & $4(1 \cdot 7)$ \\
\hline Depot injection & $1(0.5)$ & $0(0.0)$ & $0(0.0)$ \\
\hline Intrauterine device & $3(1.6)$ & $0(0.0)$ & $2(0.9)$ \\
\hline \multicolumn{4}{|l|}{ Previous contraceptives: } \\
\hline Oral & $42(22 \cdot 4)$ & $8(13 \cdot 8)$ & $8(3 \cdot 5)$ \\
\hline Depot injection & $1(0.5)$ & $0(0 \cdot 0)$ & $0(0 \cdot 0)$ \\
\hline Intrauterine device & $1(1 \cdot 6)$ & $0(0 \cdot 0)$ & $2(0.9)$ \\
\hline Parous women & $187(100)$ & $21(36 \cdot 2)$ & $50(21 \cdot 6)$ \\
\hline Parity per woman & $1.4(\mathrm{SD} 0.6)$ & $1.4(\mathrm{SD} 0.8)$ & $1.5(\mathrm{SD} 0.9)$ \\
\hline Ever and current smokers & $4(2 \cdot 1)$ & $2(3 \cdot 4)$ & $1(0.43)$ \\
\hline Ever and current regular alcohol & $0(0.0)$ & $2(3.45)$ & $2(0.90)$ \\
\hline
\end{tabular}

Unless stated otherwise, numbers in parentheses are percentages. $\mathrm{MCH}=$ Maternal and child health clinic. 
Table 2 Frequencies of menstrual alterations by exposure groups

\begin{tabular}{|c|c|c|c|c|c|}
\hline & $\begin{array}{l}\mathrm{MCH} \\
\text { women }\end{array}$ & $\begin{array}{l}\text { Low } \\
\text { exposure }\end{array}$ & $\begin{array}{l}\text { High } \\
\text { exposure }\end{array}$ & $\begin{array}{l}\text { High } \\
v M C H\end{array}$ & $\begin{array}{l}\text { High } \\
\text { v low }\end{array}$ \\
\hline $\begin{array}{l}\text { No of subjects } \\
\text { Increased irregularity of cycles } \\
\text { Increased duration of cycles } \\
\text { Increased menstrual amount } \\
\text { Decreased menstrual amount } \\
\text { Increased menstrual duration } \\
\text { Increased frequency of dysmenorrhoea } \\
\text { Decreased frequency of dysmenorrhoea } \\
\text { Increased severity of dysmenorrhoea } \\
\text { Decreased severity of dysmenorrhoea } \\
\text { Severe dysmenorrhoea }\end{array}$ & $\begin{array}{l}187 \\
20(10 \cdot 7) \\
20(10 \cdot 7) \\
11(5 \cdot 9) \\
38(20 \cdot 3) \\
4(2 \cdot 1) \\
6(3 \cdot 2) \\
0(0 \cdot 0) \\
1(0 \cdot 5) \\
0(0 \cdot 0) \\
3(1 \cdot 6)\end{array}$ & $\begin{array}{l}58 \\
7(12 \cdot 1) \\
6(10 \cdot 3) \\
7(12 \cdot 1) \\
15(25 \cdot 9) \\
0(0 \cdot 0) \\
8(13 \cdot 8) \\
4(6 \cdot 9) \\
7(12 \cdot 1) \\
4(6 \cdot 9) \\
1(1 \cdot 7)\end{array}$ & $\begin{array}{l}231 \\
27(11 \cdot 7) \\
26(11 \cdot 3) \\
23(10 \cdot 0) \\
60(26 \cdot 0) \\
6(2 \cdot 6) \\
36(15 \cdot 6) \\
24(10 \cdot 4) \\
39(16 \cdot 9) \\
24(10 \cdot 4) \\
20(8 \cdot 7)\end{array}$ & $\begin{array}{l}\text { NS } \\
\text { NS } \\
\text { NS } \\
\text { NS } \\
\text { NS } \\
<0.001 \\
<0.001 \\
<0.001 \\
<0.001 \\
<0.001\end{array}$ & $\begin{array}{l}\text { NS } \\
\text { NS } \\
\text { NS } \\
\text { NS } \\
\text { NS } \\
\text { NS } \\
\text { NS } \\
\text { NS } \\
\text { NS } \\
\text { NS }\end{array}$ \\
\hline
\end{tabular}

NS $=$ Not significant at $p<0.05$. Numbers in parentheses are percentages.

The analysis was based on the data of 476 women after excluding 19 women who were aged over 40, four women with thyroid disease, and two women with primary amenorrhoea confirmed by a physician. Statistical analyses were performed with standard contingency tables and tests of statistical significance ( $\chi^{2}$, Fisher's test, and Student's $t$ test). Stratified analyses and Mantel-Haenszel procedures were also used, where appropriate, to control for known possible confounders.

\section{Results}

The high exposure group was similar in relevant personal characteristics to the low exposure group in the same factory (table 1). Exceptionally few women in all groups were smokers or drinkers. The women from maternal and child health centres were slightly older than the factory women and differed in marital state (all were married) and race (proportionally more Malay women). Few women were currently using hormonal contraceptives or intrauterine devices (this finding is similar to that of a recent community survey of women of reproductive $\mathrm{age}^{8}$ ). The women from maternal and child health centres, however, had a higher rate of previous use of hormonal contraceptives.

The most common cycle irregularity was increased cycle duration (short cycles were reported in one woman, and both long and short cycles in another); both increased and decreased amounts of menstrual flow and only increased duration of menstruation were reported. No statistically significant differences occurred in the frequencies of cycle irregularity or

Table 3 Association of menstrual changes with exposure to toluene

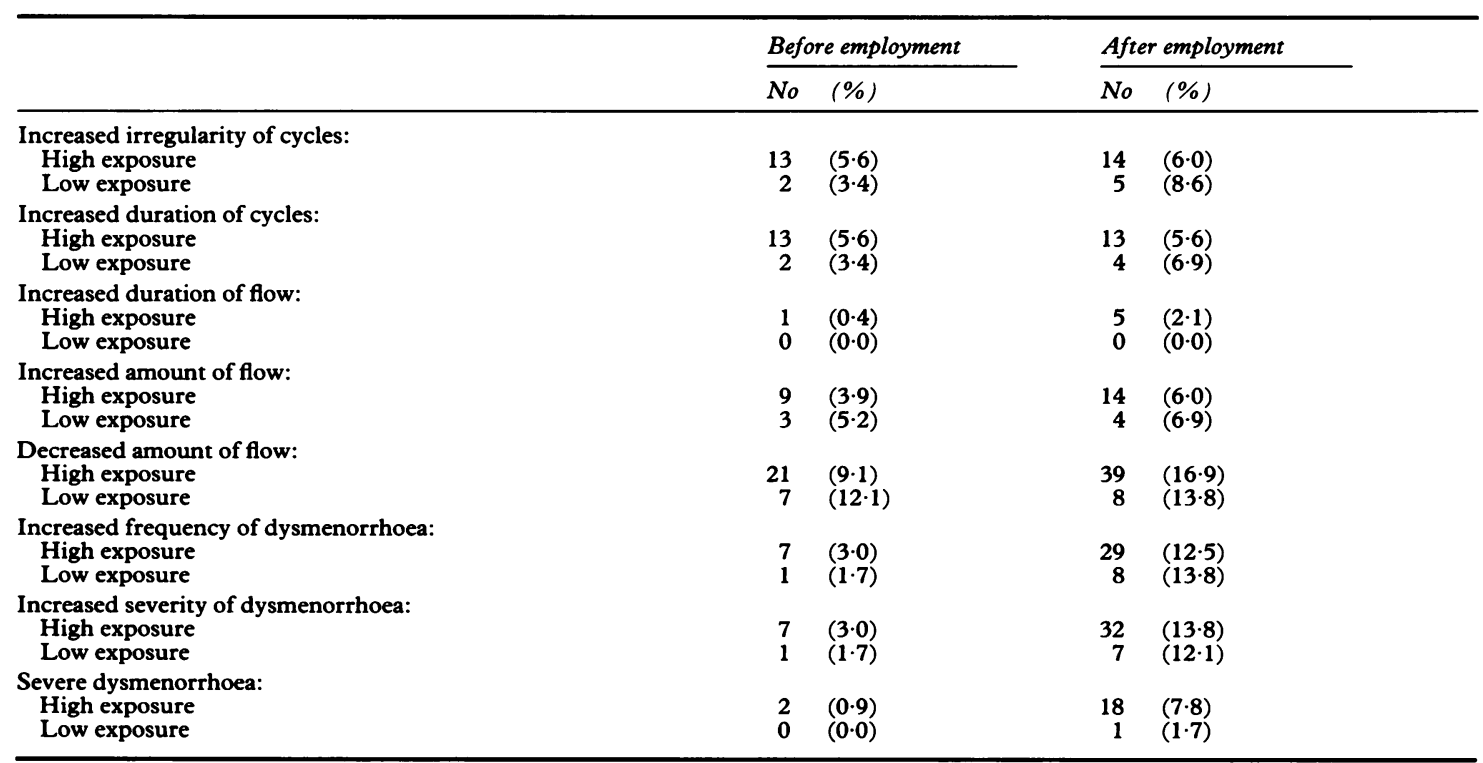

None of the differences were significant. 
alterations in the amount or duration of menstrual flow between groups. Although only married and parous women were found among the maternal and child health centre control group, the results were essentially similar when the data were examined by stratifying on marital state or parity.

Alterations in frequency and severity of dysmenorrhoea and the prevalence of severe dysmenorrhoea were more common in the high exposure group of women compared with the women from maternal and child health centres (table 2). These differences were not entirely explained by parity, hormonal contraceptive use, or employment in production jobs, and they remained highly significant after adjustment for these factors in stratified analyses with the Mantel-Haenszel procedure. The rates for dysmenorrhoeic complaints in the high exposure group, however, were not statistically significant when compared with the factory group with low exposure to toluene.

If changes in menstrual function were indeed associated specifically with high exposure to toluene in the factory, such changes after employment might be expected to occur more often in the high exposure than in the low exposure group. The results, however, suggest that both groups were likely to experience similar magnitudes of changes in menstrual function after employment at the factory (table 3).

\section{Discussion}

The present study generally does not support the findings of previous studies reporting a higher incidence of menstrual disorders in women occupationally exposed to toluene. Many factors, both personal and environmental, are known to influence menstrual function. For working women, menstrual functions are especially likely to be influenced by physical and psychological stress resulting from events in personal life and changes in environment at home and in the workplace. Both the factory control and exposed groups in this study performed similar routine and repetitive jobs sitting down, during regular daytime hours. The influence of workplace stressors such as shiftwork, heavy manual lifting, noise, and other chemical exposures could be ruled out in the workers with high exposure to toluene. Some of the women in the factory control group were exposed to low levels of noise, lead, methanol, methyl ethyl ketone, and other chemicals. These are possible workplace stress factors and may arguably increase the frequencies of menstrual disorders in this group of women, thus possibly obscuring a true difference in rates between the factory exposure groups.

The external control group employed were healthy women who attended community based maternal and child health service clinics for routine care and monitoring of their pregnancies. The women who used these public health services tended to have a lower socioeconomic background than the rest of the population, and many of them were currently or previously manufacturing production workers. In this respect, they were comparable with the women exposed to toluene in the factory. At the same time, it was considered that their data were likely to reflect the background rates of both menstrual and reproductive disorders for this socioeconomic class of women in the community.

The rates for cycle irregularity and altered menstrual duration and amount were remarkably similar in all groups compared. Polymenorrhoea and menorrhagia were the major findings in previous studies of women exposed to toluene, but there is clearly no evidence from this present study that dysfunctional uterine bleeding was likely to result from exposure to toluene.

Based on comparison with women attending maternal and child health clinics, it would appear possible that high exposure to toluene might result in more frequent and severe dysmenorrhoea. Age at menarche, parity, and hormonal contraceptive use, however, are known to influence the rates of dysmenorrhoea. ${ }^{8}$ Furthermore, the reporting of severe dysmenorrhoea, defined in terms of help seeking behaviour, was liable to be influenced by organisation and behavioural factors that vary among different employed groups of persons. Although the higher rates for dysmenorrhoea in the high exposure to toluene group were not completely explained by lower rates of parity or use of contraceptives, other personal and environmental factors (especially psychosocial and organisational) would need to be taken into account and these might well vary for different employed groups of women even within the same industry.

Comparison with the low exposure group of women within the same factory would thus appear to provide more valid results. Assuming that other exposures in the workplace were not likely to confound the results in a negative way, the evidence in this study does not strongly support a specific association between dysmenorrhoea and exposure to toluene. Furthermore, changes in personal and behavioural characteristics are likely to occur after entering employment. The results of analyses that used the subjects as their own controls (table 3) also failed to show any clear association between changes in menstrual function (dysmenorrhoea included) after employment and high exposure to toluene. It would thus be difficult to attribute the increase in menstrual disorders to toluene alone and not to some other mutable behaviourable or work related factors at the same time.

In conclusion, we found no evidence of an association between dysfunctional uterine bleeding and 
specific exposure to toluene. It is uncertain whether dysmenorrhoea is associated specifically with exposure to toluene as many other personal and work related factors were also likely to influence menstrual function.

We thank the management and staff of the factory and the staff and patients at the maternal and child health services of the Ministry of Health for their cooperation, and $\operatorname{Dr} M M$ Thein, $\mathrm{Ms} \mathrm{Ng}$ Yuen Ling, and Julie Tan for their assistance in the study.

Requests for reprints to: $\mathrm{Dr}$ T P Ng, Department of Community, Occupational, and Family Medicine, National University of Singapore, Lower Kent Ridge, Singapore 0511.
1 Michon S. Disturbances of menstruation in women working in an atmosphere polluted with aromatic hydrocarbons. Polski Lekarski 1965;20,44:1648-9.

2 Syrovadko ON, Skornin VF, Prońkova YeN, et al. Influence of working conditions on the state of health and certain specific functions of women working with white spirit. Gig $\operatorname{Tr} \operatorname{Prof}$ Zabol 1973;6:5-8.

3 Syrovadko ON, Malsheva ZV. Work conditions and their effects on certain specific functions among women who are engaged in the production of enamel-insulated wire. Gig Tr Prof Zabol 1977;4:25-8.

4 Syrovadko ON. Working conditions and the state of health of women working with organosilicon varnishes containing toluene. Gig Tr Prof Zabol 1977;12:15-19.

5 Barlow SM, Sullivan FM. Reproductive hazards of industrial chemicals. London: Academic Press, 1982:538-49.

6 Foo SC, Phoon WO, Khoo NY. Toluene in blood after exposure to toluene. Am Ind Hyg Assoc J 1988;49:255-8.

7 Foo SC, Jeyaratnam J, Koh D. Chronic neurobehavioural effects of toluene. Br J Ind Med 1990;47:480-4.

$8 \mathrm{Ng}$ TP, Tan NCK, Wansaichong GKL. A prevalence survey of dysmenorrhoea in female residents aged 15-54 in Clement Town, Singapore. Anns Acad Med Singapore (in press).

Accepted 17 February 1992

\section{Vancouver style}

All manuscripts submitted to the $B r J$ Ind Med should conform to the uniform requirements for manuscripts submitted to biomedical journals (known as the Vancouver style).

The $\mathrm{Br} J$ Ind Med, together with many other international biomedical journals, has agreed to accept articles prepared in accordance with the Vancouver style. The style (described in full in $\mathrm{Br}$ Med J, 24 February 1979, p 532) is intended to standardise requirements for authors.

References should be numbered consecutively in the order in which they are first mentioned in the text by Arabic numerals above the line on each occasion the reference is cited (Manson ${ }^{1}$ confirmed other reports $\left.{ }^{2-5} \ldots\right)$. In future references to papers submitted to the $\mathrm{Br} J$ Ind Med should include: the names of all authors if there are six or less or, if there are more, the first three followed by $e t$ al; the title of journal articles or book chapters; the titles of journals abbreviated according to the style of Index Medicus; and the first and final page numbers of the article or chapter.

Examples of common forms of references are:

1 International Steering Committee of Medical Editors. Uniform requirements for manuscripts submitted to biomedical journals. Br Med J 1979;1:532-5.

2 Soter NA, Wasserman SI, Austen KF. Cold urticaria: release into the circulation of histamine and eosino-phil chemotactic factor of anaphylaxis during cold challenge. N Engl J Med 1976;294:687-90.

3 Weinstein L, Swartz MN. Pathogenic properties of invading micro-organisms. In: Sodeman WA Jr, Sodeman WA, eds. Pathologic physiology: mechanisms of disease. Philadelphia: W B Saunders, 1974:457-72. 